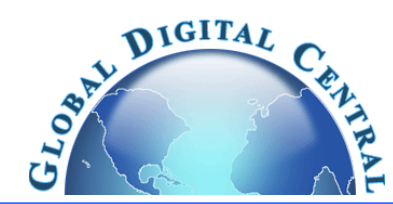

Frontiers in Heat and Mass Transfer

\title{
MHD FLOW AND HEAT TRANSFER OF AN EYRING - POWELL FLUID OVER A LINEAR STRETCHING SHEET WITH VISCOUS DISSIPATION - A NUMERICAL STUDY
}

\author{
P.V. Satya Narayana ${ }^{1 *}$, Nainaru Tarakaramu ${ }^{1}$, S. Moliya Akshit ${ }^{2}$, Jatin P. Ghori ${ }^{2}$ \\ ${ }^{1}$ Fluid Dynamics Division, SAS, VIT University, Vellore - 632 014, T.N, India \\ ${ }^{2}$ School of Mechanical and Building Sciences, VIT University, Vellore - 632 014, T.N, India.
}

\begin{abstract}
The present work is devoted to study the numerical simulation of steady magnetohydrodynamic flow and heat transfer of an Eyring-Powell fluid over a stretching sheet with viscous dissipation. The fluid is taken to be two dimensional electrically conducting and the flow is induced by a stretching surface. The basic governing partial differential equations of non-Newtonian fluid are reduced into the coupled nonlinear ordinary differential equations by using similarity transformations. The resulting ordinary differential equations are then solved numerically using shooting method with fourth order Runge- Kutta scheme. The effects of Hartmann number, Eckert number, Grashoff number and Eyring-Powell fluid parameters on the velocity, temperature, skin friction and Nusselt number are analyzed graphically. The result reveals that the effects of non- Newtonian fluid parameters $\gamma$ and $\beta$ on velocity and temperature profiles are completely dissimilar. A comparison with the earlier available work shows excellent agreement.
\end{abstract}

Keywords: Numerical approach; MHD; Eyring-Powell fluid; viscous dissipation; stretching sheet.

\section{INTRODUCTION}

The study of dynamics of non-Newtonian fluids has been an interested area of current research because of its vast applications in several fields of science and technology. Examples of such fluids include coal-oil slurries, yoghurt, lubricants, toothpaste, paints, clay coating and suspensions, grease, physiological liquids (blood, bile, synovial fluid) etc. The broad usages of such fluids have encouraged modern researchers to explore extensively the behavior of different nonNewtonian fluid models such as power- law model, Casson model, second order Reiner-Rivlin differential fluid models etc. Among these, the Eyring-Powell fluid model, though mathematically more complex, can be used in some cases to explain the behavior of polymer solutions and viscoelastic suspensions over a wide range of shear rates (Akbar et al., 2015; Chen., 1998; Grubka and Bobba., 1985; Hayat et al., 2009). (Hayat et al., 2013) examined the numerical analysis of magnetic field effects on Eyring-Powell fluid flow towards a stretching sheet. Hayat et al., (2013) analyzed the MHD peristaltic transport of Eyring-Powell fluid with slip conditions. MHD flow of Powell-Eyring fluid over a various flow fields has been observed by (Hina., 2016; Khan et al., 2014). Recently, Khan et al. (2015) presented the combined effects of heat and mass transfer in Jeffrey fluid over a stretching sheet in the presence of power law form of temperature and concentration. Some remarkable attempts have been made to study the influence of MHD on various flow situations Manisha Patel., (2009); Osalusi., 2008; Powell and Eyring., (1944). Raju et al., (2014) analysed the influences of viscous dissipation and joule heating on MHD forced convective flow over a fixed horizontal channel.

Many investigations were made to examine the flow over various flow fields under different heat and mass transfer effects (Satya
Narayana., (2015); Satya Narayana and Harish Babu., 2016). It is known that the majority of researchers (Satya Narayana et al., 2015; Sheikholeslami et al., 2015; Sheikholeslami et al., 2015) have been used analytical methods (HAM) to solve non- Newtonian flow type problems and these type of problems with numerical techniques are appears to be scant. So, a mathematical model has been proposed and analyzed numerically, the effect of viscous dissipation on MHD nonNewtonian flow over a linear stretching surface. The governing system of partial differential equations has been transformed using the suitable similarity transformations into non-linear ordinary differential equations which are then solved by using fourth order Runge- Kutta method along with shooting technique. The outline of the work as follows. In section 2 we present the mathematical formulation. The results and discussion are presented in section 3. Lastly, Section 4 encloses the main inferences.

\section{MATHEMATICAL FORMULATION OF THE PROBLEM}

We consider the steady laminar boundary-layer flow and heat transfer of an incompressible, electrically conducting non-Newtonian EyringPowell fluid past a linear stretching sheet with viscous dissipation. The flow is generated by the action of two equal and opposite forces along the $\mathrm{x}$ - axis and the sheet is assumed to be linearly stretching. A Cartesian coordinate system is chosen in such a way that $\mathrm{x}$-axis is along the stretching surface and the y-axis perpendicular to it [see Fig.1]. An applied magnetic field of strength $B_{0}$ is encountered normal to the flow direction. Further it is assumed that the induced magnetic field is negligible due to small magnetic Reynolds numbers. The stress tensor 
in the Eyring-Powell model for non-Newtonian fluids is given by (Siddiqui., 2013)

$$
\tau_{i j}=\mu \frac{\partial u_{i}}{\partial x_{j}}+\frac{1}{\beta} \sinh ^{-1}\left(\frac{1}{C} \frac{\partial u_{i}}{\partial x_{j}}\right)
$$

In which $\mu$ is the dynamic viscosity, $\beta$ and $\mathrm{C}$ are the material fluid parameters. We take the second order approximation of function as

$\sinh ^{-1}\left(\frac{1}{C} \frac{\partial u_{i}}{\partial x_{j}}\right) \cong \frac{1}{C} \frac{\partial u_{i}}{\partial x_{j}}-\frac{1}{6}\left(\frac{1}{C} \frac{\partial u_{i}}{\partial x_{j}}\right)^{3},\left|\frac{1}{C} \frac{\partial u_{i}}{\partial x_{j}}\right| \ll<1$

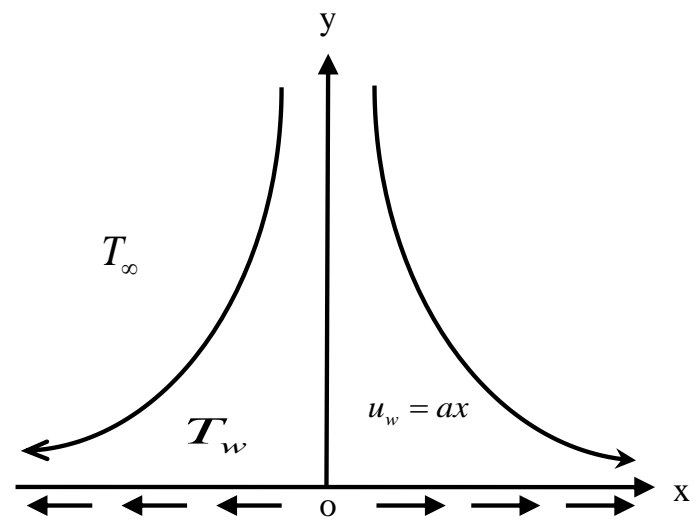

Fig. 1 Geometry of the problem

The boundary layer equations containing the continuity, linear momentum and energy can be written as (see Refs Hayat et al., 2013; Hayat et al., 2013)

$$
\frac{\partial u}{\partial x}+\frac{\partial v}{\partial y}=0
$$

$u \frac{\partial u}{\partial x}+v \frac{\partial u}{\partial y}=\left(v+\frac{1}{\rho \beta_{1} c}\right) \frac{\partial^{2} u}{\partial y^{2}}-\frac{1}{2 \rho \beta_{1} c^{3}}\left(\frac{\partial u}{\partial y}\right)^{2}\left(\frac{\partial^{2} u}{\partial y^{2}}\right)$

$$
-\frac{\sigma B_{0}^{2}}{\rho} u+g \beta_{T}\left(T_{w}-T_{\infty}\right)
$$

$u \frac{\partial T}{\partial x}+v \frac{\partial T}{\partial y}=\frac{k}{\rho c_{p}} \frac{\partial^{2} T}{\partial y^{2}}+\frac{\mu}{\rho c_{p}}\left(\frac{\partial u}{\partial y}\right)^{2}$

The boundary conditions are defined by

$u=u_{w}(x)=a x, \quad v=0, \quad T=T_{w}(x)=T_{\infty}+b x^{2} \quad$ at $y=0$

$u \rightarrow 0, \quad T \rightarrow T_{\infty} \quad$ as $y \rightarrow \infty$.

where $\mathrm{u}$ and $\mathrm{v}$ denote the velocity components in $\mathrm{x}$ - and $\mathrm{y}$ - directions respectively; $\mathrm{T}$ is the fluid temperature; $\rho$ is the fluid density; $\mu$ is the dynamic viscosity; $\kappa$ is the thermal conductivity; $c_{p}$ is the specific heat at constant pressure; $g$ is the acceleration due to gravity; $\beta_{\mathrm{T}}$ is the coefficient of thermal expansion; $a, b$ are the constants; $u_{w}(x)$ is the velocity of stretching surface.

Introducing the following similarity transformations

$\eta=\sqrt{\frac{a}{v}} y, \quad u=a x f^{\prime}(\eta), \quad v=-\sqrt{a v} f(\eta), \quad \theta=\frac{T-T_{\infty}}{T_{w}-T_{\infty}}$

Making use of transformations (5), Eqs. (2) and (3) takes the form $f^{\prime \prime}(1+\gamma)-\gamma \beta f^{\prime \prime 2} f^{\prime \prime}-M^{2} f^{\prime}+\theta \lambda+f f^{\prime \prime}-f^{\prime 2}=0$

$2 f^{\prime} \theta-f \theta^{\prime}-\frac{\theta^{\prime \prime}}{\operatorname{Pr}}-\operatorname{Ec}\left(f^{\prime \prime}\right)^{2}=0$

The boundary conditions becomes

$$
f=0, \quad f^{\prime}=1, \theta=1 \quad \text { at } \eta=0
$$$$
f^{\prime} \rightarrow 0, \theta \rightarrow 0, \eta \rightarrow \infty
$$

Where $\gamma=\frac{1}{\beta_{1} c \mu}$ and $\beta=\frac{\left(u_{w}\right)^{2}}{2 v c^{2}}$ are the material constants of the Eyring- Powell fluid and $M^{2}=\frac{\sigma B_{0}^{2}}{a \rho}$ is the Magnetic field parameter, $\lambda=\frac{g \beta_{T}\left(T_{W}-T_{\infty}\right)}{a^{2} x}$ is the Grashoff number, $\operatorname{Pr}=\frac{\mu c_{p}}{k}$ is the Prandtl number, $E_{c}=\frac{a^{2}}{b c_{p}}$ is the Eckert number.

The Skin friction is given by

$\operatorname{Re}^{-\frac{1}{2}} C_{f}=(1+\gamma) f^{\prime \prime}(0)-\frac{\beta \gamma}{3} f^{\prime \prime 3}(0)$

The local Nusselt number is given by

$N u_{x} \operatorname{Re}_{x}^{-1 / 2}=-\theta^{\prime}(0)$

\section{RESULT AND DISCUSSION}

The system of coupled non-linear equations (6) and (7) with the boundary conditions (8) are solved numerically using the shooting method with fourth order Runge-Kutta scheme. In order to illustrate the salient features of the model, the numerical results are presented in Figs.2-7 and compared with the existing results. The results of this comparison are given in Table.1 with those of Refs. (Skelland., 1967; Wilkinson., 1960). It can be seen from this table that excellent agreement between the results exists. The effects of Eyring-Powell fluid parameters $\gamma$ and $\beta$ on the velocity and temperature profiles are displayed in Figs. 2(a)-2(d) respectively. It is witnessed that $f^{\prime}(\eta)$ increase with increasing values of $\gamma$ and have quite reverse consequences on $\theta(\eta)$. Physically, high $\gamma$ values relate to solid-like behavior. This is due to the occurrence of yield stress which decreases the velocity. These outcomes are identical as distinguished in Ref. (Grubka and Bobba., 1985; Hina., 2016). It is also noticed that the velocity of Newtonian fluid is far away from the sheet than to the nonNewtonian fluid. Further, an opposite behavior can be observed for $f^{\prime}(\eta)$ and $\theta(\eta)$ with the increase of $\beta$. It is also seen that the impact of $\beta$ on $f^{\prime}(\eta)$ and $\theta(\eta)$ profiles is very less.

Figs. 3(a)-3(b) elucidate the effect of magnetic parameter $M$ on the velocity and temperature profiles. It is observed that $f^{\prime}(\eta)$ declines with rise of $M$ along the surface. Physically, greater the Lorentz force gives the lesser velocity as this acts as a retarding force. On the other hand, $\theta(\eta)$ increase with increasing values of $M$. Figs. 4(a)-4(b), respectively, display the velocity and temperature profiles for various values of Eckert number $E c$. It is noticed that $f^{\prime}(\eta)$ and $\theta(\eta)$ increase with the increase of Ec. This is due to the fact that heat energy is stored in the liquid due to the frictional heating. Thus the effect of increasing Ec is to improve the temperature at any point in the thermal boundary layer.

The velocity and temperature distributions for different values of Grashoff number $\lambda$ are defined in Figs. 5(a)-5(b) respectively. It is clear that an increase in $\lambda$ leads to rise in the value of velocity due to enhancement in buoyancy force. Physically, $\lambda>0$ means heating of the fluid by cooling the boundary surface. It is also observed that, the minimum velocity values are observed in the absence $(\lambda=0)$ of buoyancy force. On the other hand, $\theta(\eta)$ decrease with increasing values of $\lambda$. Figs. 6(a)-6(b) demonstrate the deviation of skin friction and Nusselt number against magnetic field parameter $M$ for different values of $\lambda$, respectively. It is observed that, the skin friction rises and Nusselt number declines with increasing of $\lambda$. In addition, it is also noted that the heat transfer rate decrease with increasing values of $M$. These outcomes obviously sustained from the physical point of view.

Figs. 7(a)-7(b) demonstrate the variation of skin friction coefficient and Nusselt number with $M$ for various values of $\beta$. It is noticed that both skin friction coefficient and Nusselt number declines with increase of $\beta$. It is also hypothesized that the rise in $\beta$ will increase the resistance of fluid motion. Hence the velocity boundary layer thickness reduces which results in lower values of skin friction coefficient. 


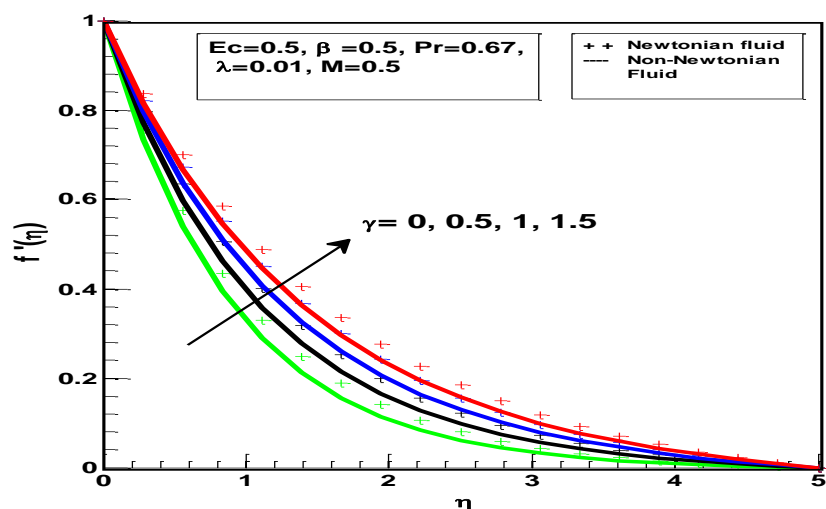

(a) Velocity profile

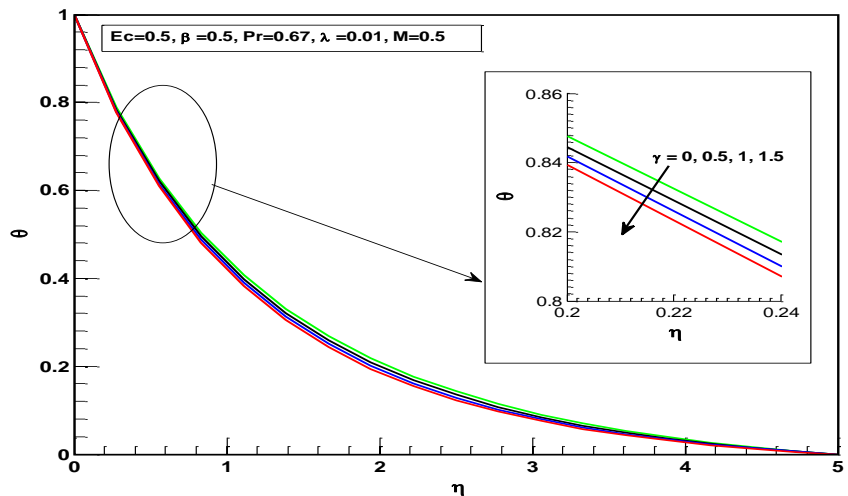

(b) Temperature profile

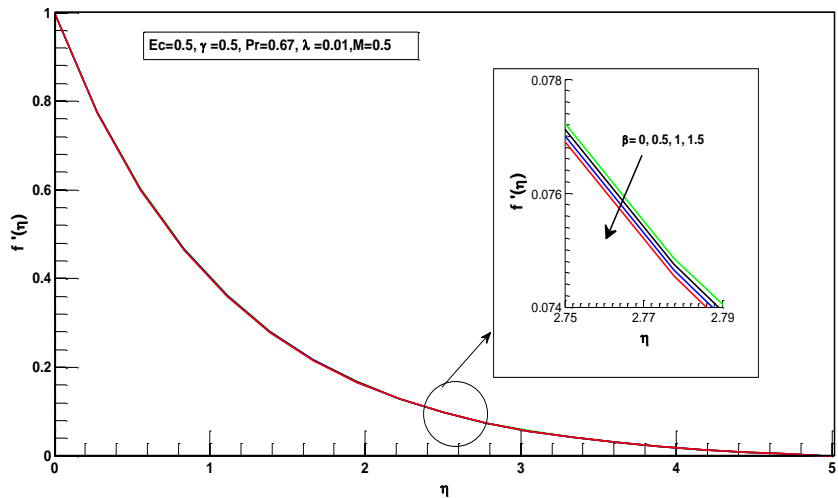

(c) Velocity profile

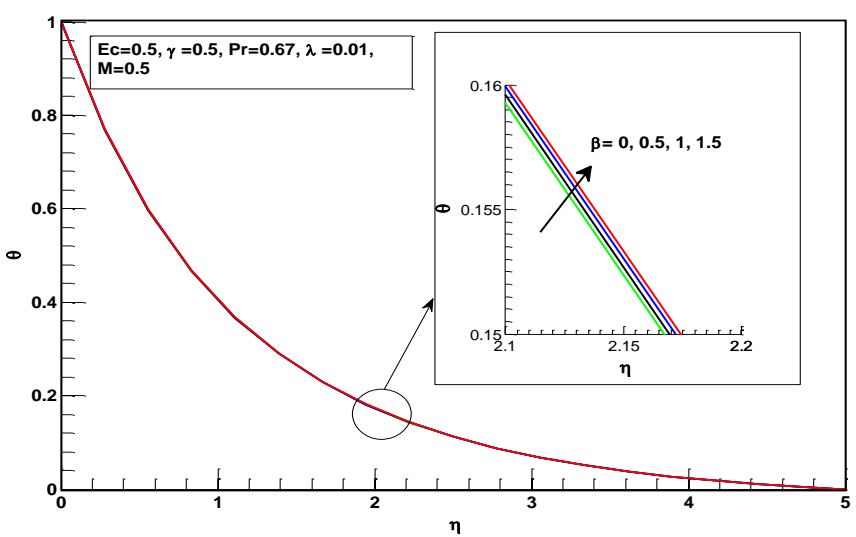

(d) Temperature profile

Fig. 2 Velocity and Temperature profiles for various values of $\gamma$ and $\beta$.

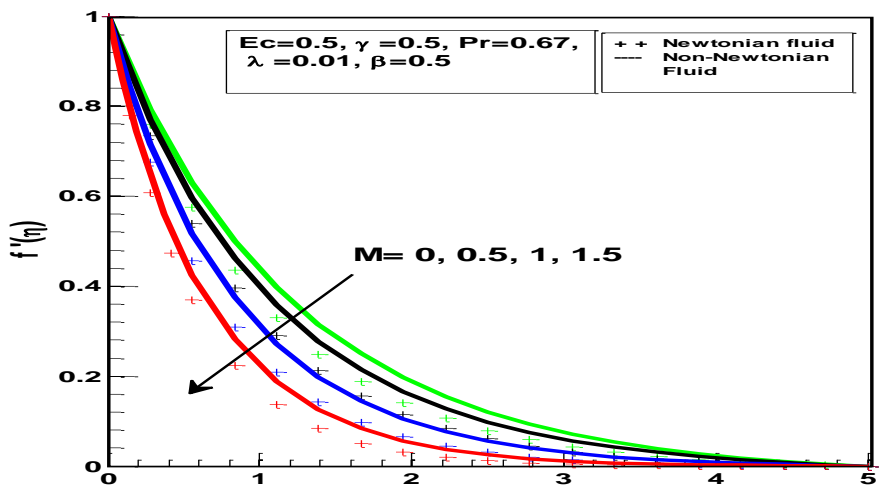

(a) Velocity Profile

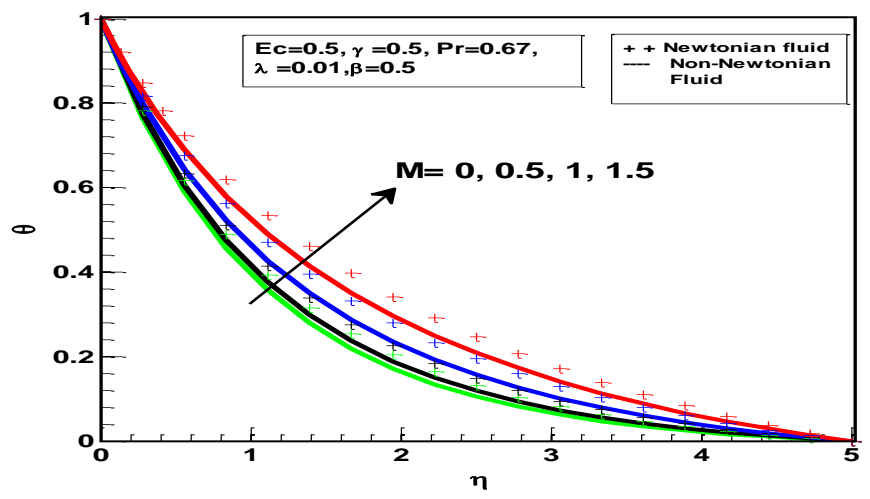

(b) Temperature profile

Fig. 3 Velocity and Temperature profiles for various values of $M$

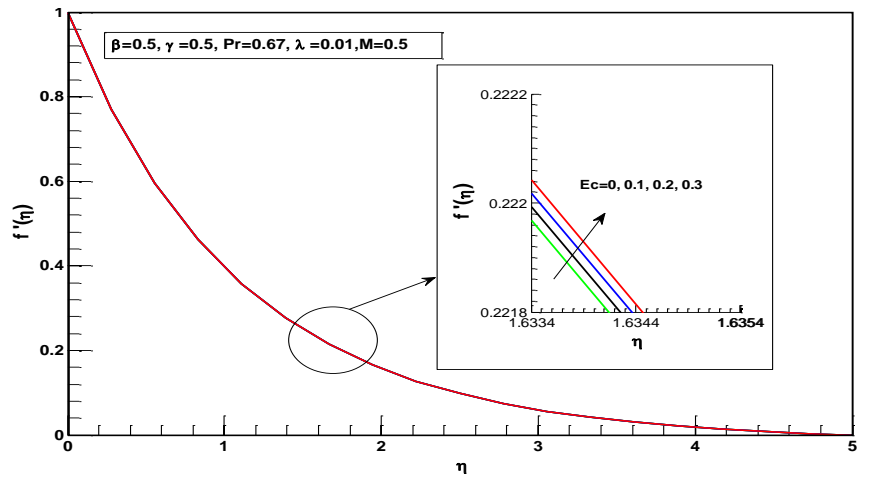

(a) Velocity Profile.

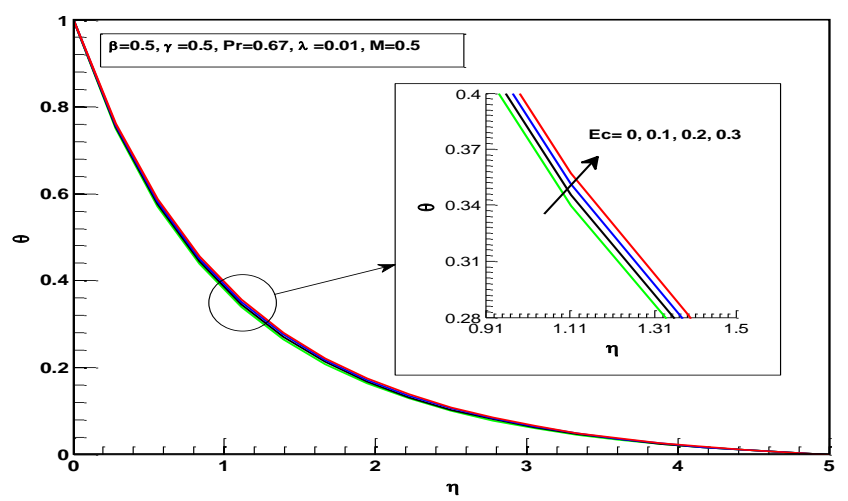

(b) Temperature Profile

Fig. 4 Velocity and Temperature Profiles for various values of $E c$ 


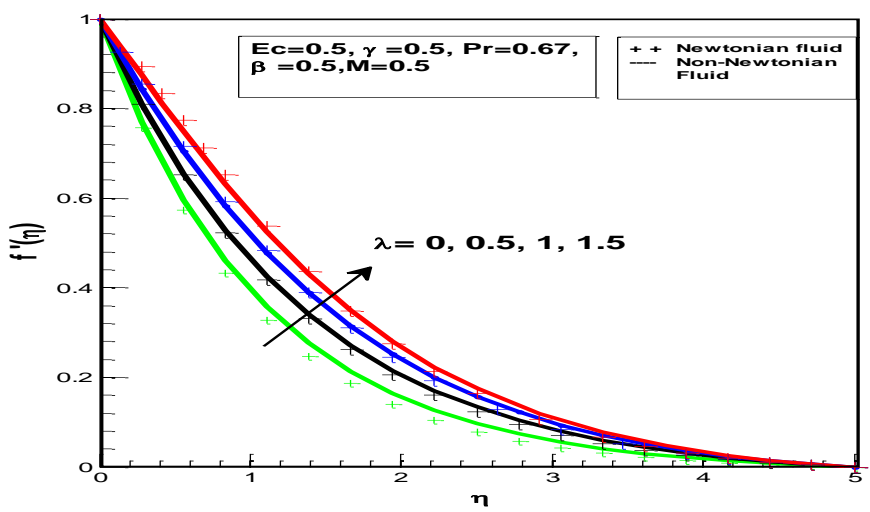

(a) Velocity profile

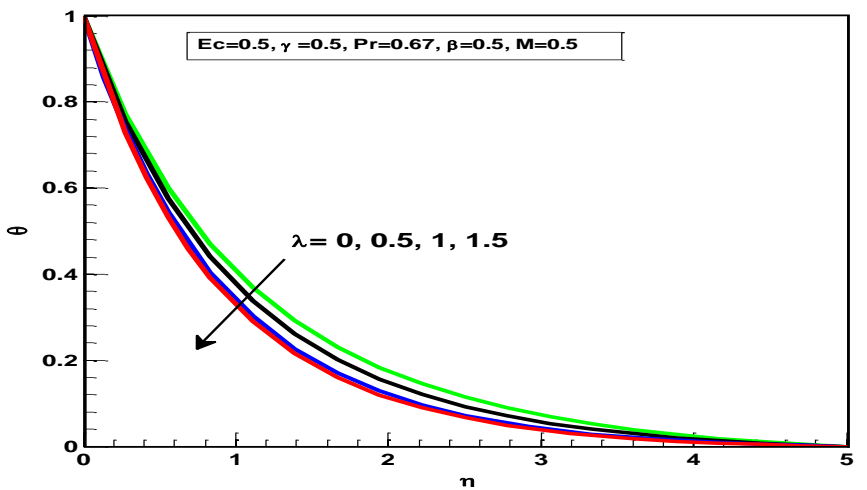

(b) Temperature profile

Fig. 5 Velocity and Temperature profile for various values of $\lambda$

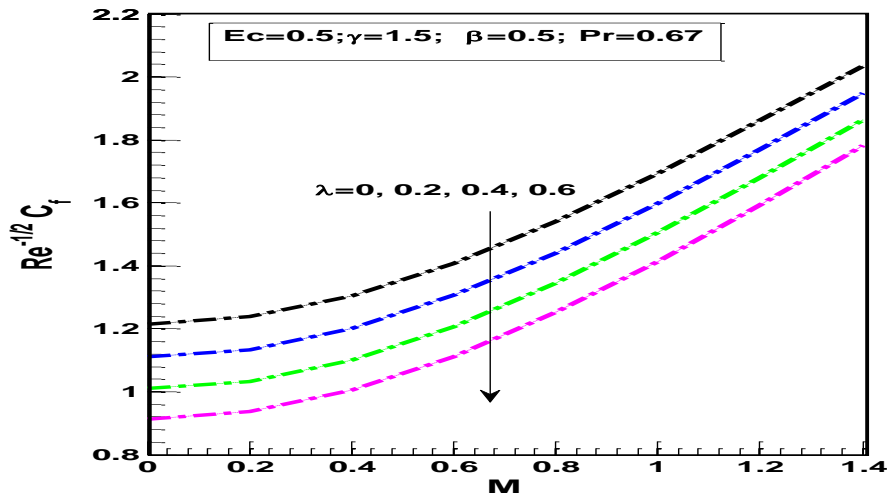

(a) Skin friction coefficient profile

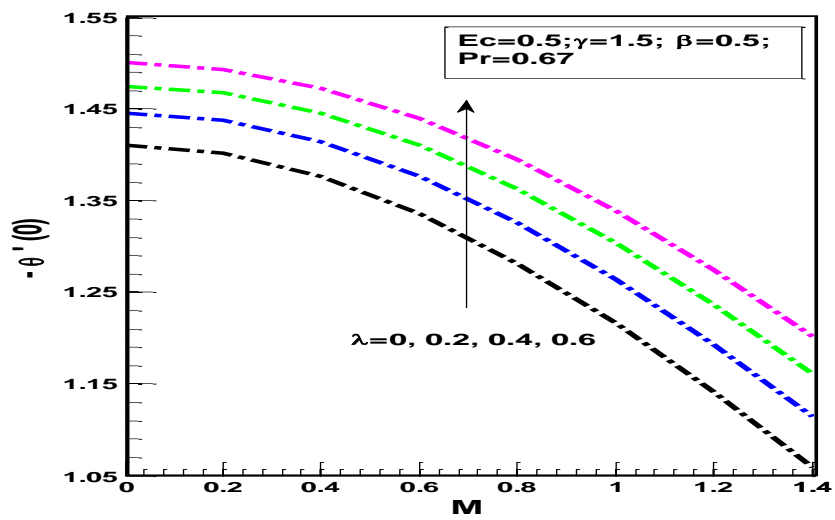

(b) Nusselt number profile

Fig. 6 Skin friction coefficient and Nusselt Number for various values of $\lambda$

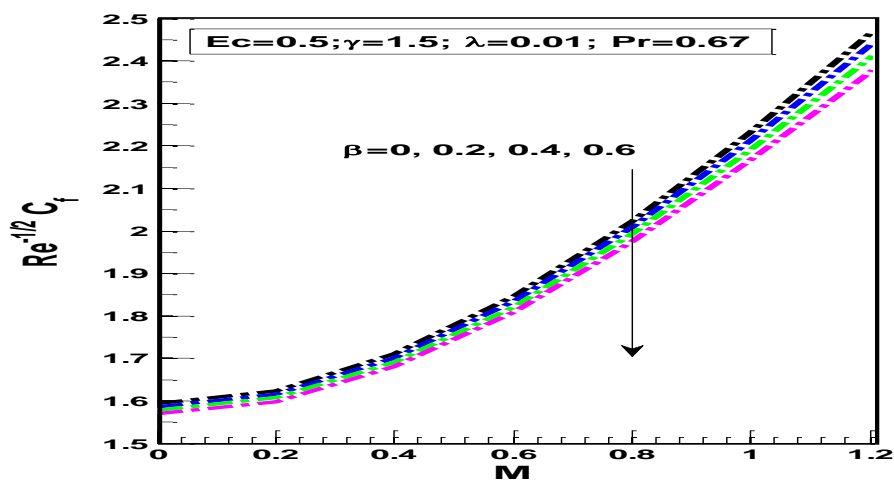

(a) Skin friction coefficient profile

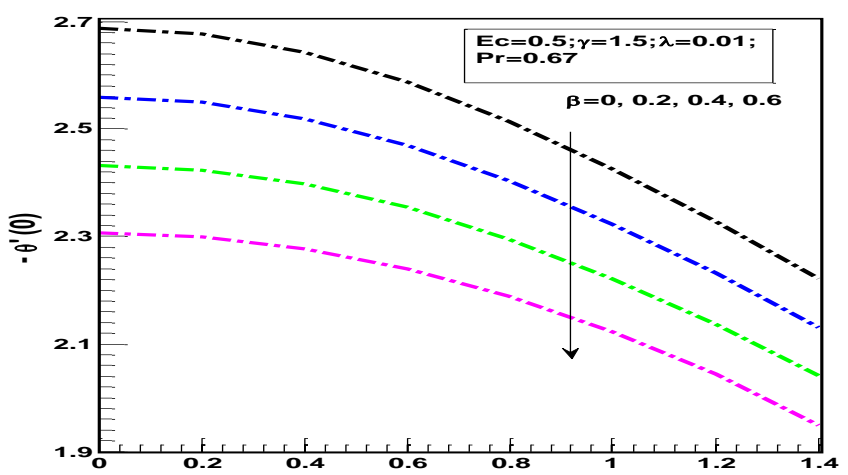

(b) Nusselt number profile

Fig. 7 Skin friction coefficient and Nusselt Number for various values of $\beta$

Table 1 Comparison of local Nusselt number $N u_{x} \operatorname{Re}_{x}^{-1 / 2}$ when $\mathrm{M}=\mathrm{Ec}=$ $\gamma=\beta=\lambda=0$ for various values of Pr.

\begin{tabular}{c|l|c|c|}
\hline Pr & $\begin{array}{l}\text { Chen } \\
(\mathbf{1 9 9 8})\end{array}$ & $\begin{array}{c}\text { Grubka } \\
\text { and Bobba } \\
\mathbf{( 1 9 8 5 )}\end{array}$ & Present \\
\hline 1 & 1.3333 & 1.33334 & 1.33333 \\
\hline 3 & 2.5097 & 2.50972 & 2.50971 \\
\hline 10 & 4.79686 & 4.79690 & 4.79689 \\
\hline
\end{tabular}

\section{CONCLUSIONS}

The main investigations of present study can be summarized as follows.

1. The effects of $\gamma$ and $\beta$ on velocity are opposite.

2. The fluid velocity in case of Newtonian fluid is predicated higher than that for the case of non- Newtonian fluid and it decreased as $\gamma$ increases.

3. It is interesting to note that the magnitude of fluid velocity increases with an increase of $E c$ and decreases with an increase in Hartmann number.

4. The temperature rises with an increasing values of $M$ and $\beta$ whereas opposite effect is seen by enhancing the value of $\lambda$.

5. The skin friction coefficients as well as Nusselt number decrease with increasing values of $\beta$.

6. $\lambda$ shows opposite effect on skin friction coefficient and rate of heat transfer coefficients. 


\section{REFERENCES}

Akbar, N.S., Ebaid, A., Khan, Z.H., 2015, "Numerical Analysis of Magnetic Field Effects On Eyring-Powell Fluid Flow towards A Stretching Sheet," J. Magn Magne. Mater. 382, 355-358. https://doi.org/10.1016/j.jmmm.2015.01.088

Chen, Ch., 1998,'Laminar Mixed Convection Adjacent To Vertical Continuously Stretching Sheets", Heat Mass Transfer. 33, 471-476.

Grubka, L.G., Bobba, K.M., 1985, "Heat Transfer Characteristics of a Continuous Stretching Surface with Variable Temperature," J. Heat transfer. 107, 248-250.

Hayat, T., Abbas, Z., Sajid, M., 2009, "MHD Stagnation Point Flow of an Upper Convected Maxwell Fluid Over A Stretching Sheet," Chaos Solitons Fractals. 39, 840-848.

https://doi.org/10.1016/j.chaos.2007.01.067

Hayat, T., Awais, M., Asghar, S., 2013, "Radiative Effects in A ThreeDimensional Flow of MHD Eyring-Powell Fluid," J. Egypt. Math Soc. 21, $379-384$.

https://doi.org/10.1016/j.joems.2013.02.009

Hayat, T., Pakdemirli, M., Aksoy, Y., "Similarity Solutions for Boundary Layer Equations of A Powell-Eyring Fluid," Math. Comp. App., $\mathbf{l 1 8}$ (2013) 62-70.

doi: $10.3390 /$ mca18010062

Hina, S., 2016, "MHD Peristaltic Transport of Eyring-Powell Fluid with Heat/Mass Transfer Wall Properties and Slip Conditions," $J$. Magn. Magne. Mater. 404, 148-158.

http://dx.doi.org/10.1016/j.asej.2015.07.012.

Khan, N.A., S Aziz, S., Khan, N.A., 2014 "MHD Flow of PowellEyring Fluid Over A Rotating Disk," J. Taiwan Inst. Chem. Eng. 45, 2859-2867.

http://dx.doi.org/10.1016/j.jtice.2014.08.018

Khan, N.A., Sultan, F., Rubbab, Q., 2015, "Optimal Solution of Nonlinear Heat and Mass Transfer in a Two-Layer Flow With NanoEyring-Powell Fluid," Results Phys. 5, 199-205.

https://doi.org/10.1016/j.rinp.2015.08.006

Manisha Patel, M.G., 2009, "Timol Numerical Treatment of PowellEyring Fluid Flow Using Method of Satisfaction of Asymptotic Boundary Conditions (MSABC)," Appl. Numerical Math. 59 (10), 2584-2592.

https://doi.org/10.1016/j.apnum.2009.04.010
Osalusi, E., Side, J., Harris, R., Clark,P., 2008, "The Effect of Combined Viscous Dissipation and Joule Heating on Unsteady Mixed Convection MHD Flow on A Rotating Cone in a Rotating Fluid," Int. Comm. Heat Mass Transfer. 35, 413-429.

https://doi.org/10.1016/j.icheatmasstransfer.2007.09.002

Wavy Channel With Traveling Thermal Waves," Propulsion Power Res. 4 (3), 150-160.

https://doi.org/10.1016/j.jppr.2015.07.002

Raju, K.V.S., Sudhakar Reddy, T., Raju, M.C., Satya Narayana, P.V., Venkataramana, S., 2014, "MHD Convective Flow Through Porous Medium in a Horizontal Channel with Insulated and Impermeable Bottom Wall," Ain Shams Eng. J. 5, 543-551.

https://doi.org/10.1016/j.asej.2013.10.007

Satya Narayana, P.V., 2015, "Effects of Variable Permeability and Radiation Absorption on MHD Mixed Convective Flow in a Vertical Powell, R.E. and Eyring, H., 1944, "Mechanism for the Relaxation Theory of Viscosity," Nature.154 (55), 427-428.

Satya Narayana, P.V., Harish Babu, D., 2016, "Numerical MHD Heat and Mass Transfer Jeffrey Fluid over a Stretching Sheet with Chemical Reaction and thermal Radiation", J. Taiwan Inst. Chem. Eng. 59, 18-25. https://doi.org/10.1016/i.jtice.2015.07.014

Satya Narayana, P.V., Venkateswarlu, B., and Devika, B., 2015, "Chemical Reaction and Heat Source Effects on MHD Oscillatory Flow in an Irregular Channel," Ain Shams Eng. J. 7, 1079-1088.

https://doi.org/10.1016/j.asej.2015.07.012

Sheikholeslami, M., Hatami, M., Domairry, G., 2015 "Numerical Simulation of Two Phase Unsteady Nanofluid Flow and Heat Transfer Between Parallel Plates in Presence of Time Dependent Magnetic Field", J. Taiwan Inst. Chem. Eng. 46, 43-50.

https://doi.org/10.1016/j.jtice.2014.09.025

Sheikholeslami, M., Ganji, D.D., Rashidi, M.M., 2015,"Ferrofluid Flow And Heat Transfer in a Semi Annulus Enclosure in The Presence of Magnetic Source Considering Thermal Radiation," J. Taiwan Inst. Chem. Eng. 47, 6-17.

https://doi.org/10.1016/i.jtice.2014.09.026

Siddiqui, A.M., Farooq, A.A., Babcock, B.S., 2013, “Two Analytical Methods Applied to Study Thin Film Flow of an Eyring-Powell Fluid on a Vertically Moving Belt," Appl. Math. Sci., 7, 3469-3478.

http://dx.doi.org/10.12988/ams.2013.34200

Skelland, A.H.P., 1967,"Non-Newtonian Flow and Heat Transfer," John Wiley, New York.

Wilkinson, J., 1960, "Non-Newtonian Fluids," Pergamon Press, Oxford. 